\title{
Fault Diagnosis in Static Converters Used in Induction Heating Systems
}

\author{
Ouahiba Fadli', Mohamed Lokmane Bendaas ${ }^{2}$, Rachid Abdessemed ${ }^{3}$ \\ ${ }^{1}$ Institute of Health and Safety, T.C. Department, Batna 2 University, Algeria \\ ${ }^{2,3}$ LEB Research Laboratory, Department of Electrical Engineering, Batna 2 University, Algeria
}

\section{Article Info \\ Article history: \\ Received Apr 27, 2018 \\ Revised Jul 18, 2018 \\ Accepted Aug 6, 2018}

\section{Keyword:}

Induction heating systems

Static converters

Fault detection and diagnosis

Spectrum analysis

Analytical redundancy residue

Current spacevector trajectory

\begin{abstract}
This paper presents different techniques on fault diagnosis in static converters used to supply and control induction heating systems. These techniques allow the detection and the location of the failed semiconductor switches. After an overview of the device with its main features in healthy state, we have afterwards focused on the fault detection and diagnosis in three electronic power converters which constitute the power generator of the induction furnace. For uncontrolled three-phase rectifier, three external methods based on the analysis of lines currents are used: Average currents method, Current space vector trajectory, called Current Park's vector approach and Spectrum analysis. For the buck converter (chopper), analytic redundancy approach, based on the residues calculation, is used. For the series resonant inverter, a simple and efficient method based on the average voltages analysis, allows the detection and the location of the power switch in fault. The obtained simulation results, in Matlab/Simulink, are presented and discussed. They reveal that the proposed diagnostic techniques are of great interest.
\end{abstract}

Copyright $\odot 2018$ Institute of Advanced Engineering and Science. All rights reserved.

\section{Corresponding Author:}

Ouahiba Fadli,

Institute of Health and Safety, T.C. Department,

Batna 2 University,

53, Route de Constantine, Fésdis, Batna 05078, Algeria.

Email:wafadli@yahoo.fr

\section{INTRODUCTION}

Induction heating is a process based on the coupling of two physical phenomena: electromagnetic induction and Joule effect. This process covers a wide range of applications, from domestic cooking, to industrial applications, such as: brazing, welding, hardening and metals melting. This is due to the very interesting features and various advantages of this heating process: high energy efficiency, good accuracy, rapidity, very high power densities, safety and cleanliness operations [1]-[3]. This wide field of induction heating applications, $(1 \mathrm{~kW}-10 \mathrm{MW})$, is the result of a technological progress in semiconductor switches and performances of the control techniques used in this field. This process allows, thus, the supply of induction furnaces with a wide frequency range $(100 \mathrm{~Hz}-500 \mathrm{kHz})$. For applications requiring higher frequencies (up to $3 \mathrm{MHz}$ ), vacuum tubes are used. However, for very high power furnaces operating at $50 \mathrm{~Hz}$, the resonant load is directly connected to the transformer, [4]-[7].

Monitoring and diagnosis of the different stages of the power generator, is a mandatory task, to ensure the availability of equipments, the service continuity and improve the device reliability [8]-[17]. In this paper, we present different diagnostic techniques of open circuit faults of semiconductor switches, in three static converters, used to supply and control of an induction heating system rated $5 \mathrm{~kW}$ at $50 \mathrm{kHz}$. These techniques allow detection and location of the failed component. After a modular presentation of the 
device, with its main features in healthy case, we focus on fault diagnosis of the three electronic converters, which constitute the power generator of the induction furnace.

For the uncontrolled three-phase bridge rectifier, three external methods, based on the analysis of AC current lines, are used: average current lines method, current Park's vector trajectory approach and spectrum analysis. For the buck converter, an internal method, called analytical redundancy technique, is applied. It is based on the calculation and analysis of the residues, between the responses of the physical system and those of different appropriate models (healthy and faulty states). For the series resonant inverter, we use a simple and effective method, based on the sign analysis of the average output voltage and the evolution of the voltages across the power switches, for detection and location of faulty component. Simulation results are presented and discussed, in Matlab/Simulink, to illustrate the effectiveness of these proposed techniques.

\section{PRESENTATION OF THE INDUCTION HEATING SYSTEM}

The synoptic diagram of the complete induction heating system is shown in Figure 1. It comprises the power generator, the induction furnace and the control stage consisting of two device control loops.

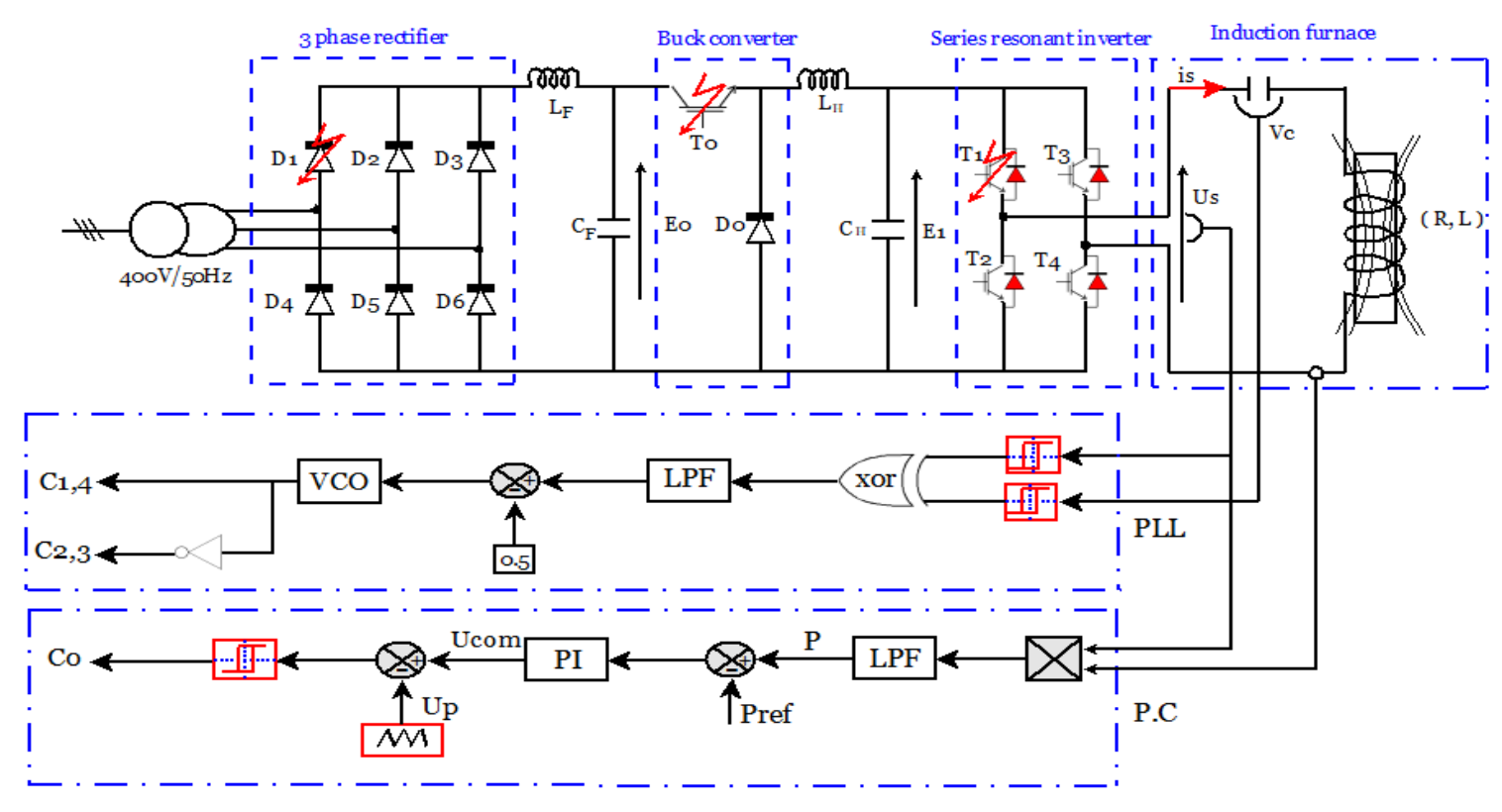

Figure 1. Induction heating system

Where: PI: linear regulator proportional-integral, PLL: phase-locked loop, PC: Power control loop, LPF: Low pass filter, VCO: Voltage controlled oscillator.

\subsection{Power stage}

The power stage, illustrated in Figure 1, consists of [18], [20]:

a. Three-phase uncontrolled bridge rectifier

b. Rectifier bridge output filter $\left(\mathrm{R}_{\mathrm{F}}, \mathrm{L}_{\mathrm{F}}, \mathrm{C}_{\mathrm{F}}\right)$

c. Buck converter (chopper) for DC bus voltage control of the resonant inverter

d. DC/DC converter output filter $\left(\mathrm{L}_{\mathrm{H}}, \mathrm{C}_{\mathrm{H}}\right)$

e. Series resonant inverter supplying the induction furnace

f. Induction furnace (inductor and thermal load) modeled by an inductive load (R, L), with a compensation capacitor (C) forming a series resonant circuit. 


\subsection{Device control stage}

The control stage includes two control loops:

a. The first one is the power control loop (PC) (Figure 1), used for DC bus voltage control, (at the input of the resonant inverter), by a linear proportional-integral (PI) regulator. It allowing the modulation of buck converter duty cycle and, thus, the control of induction furnace power [21], [22].

b. The second one is the phase-locked loop (PLL) (Figure 1) being based on the voltage controlled oscillator (VCO) [23]-[25]. It keeps the switching frequency of the series inverter very close to the resonance frequency of the load. The inverter becomes controlled by the resonant load that ensures the operation at a maximum power, with a unit power factor, even with parametric variations of the thermal load. Therefore, this operation assigns to the PLL a certain degree of robustness of the process.

\section{CHARACTERISTICS OF THE HEALTHY SYSTEM (WITHOUT DEFECTS)}

\subsection{System parameters [26]}
a. Three-phase AC source: $(50 \mathrm{~Hz}, 400 \mathrm{~V})$
b. Filter 1: $\mathrm{R}_{\mathrm{F}}=2 \Omega, \mathrm{L}_{\mathrm{F}}=10 \mathrm{mH}, \mathrm{C}_{\mathrm{F}}=3000 \mu \mathrm{F}$
c. Filter 2: $\mathrm{L}_{\mathrm{H}}=210 \mathrm{mH}, \mathrm{C}_{\mathrm{H}}=15,6 \mu \mathrm{F}$
d. Inverter input voltage: $400 \mathrm{~V}$
e. Resonant load parameters: $\mathrm{R}=26.6 \Omega, \mathrm{L}=126.7 \mu \mathrm{H}, \mathrm{C}=0.08 \mu \mathrm{F}$
f. Initial resonance frequency: $\mathrm{f}_{\mathrm{r}}=50 \mathrm{kHz}$
g. Nominal furnace power: $5 \mathrm{~kW}$
h. PI regulator parameters: $\mathrm{K}_{\mathrm{p}}=3,5 \cdot 10^{-5}, \mathrm{~K}_{\mathrm{i}}=1,1$

\subsection{Simulation results in healthy state}

Figure $2 \mathrm{a}$ depicts the output voltage of the uncontrolled three-phase rectifier $\left(\mathrm{U}_{\mathrm{r}}\right)$ and the voltage across the input filter of the DC/DC converter $\left(\mathrm{E}_{0}\right)$. Figure $2 \mathrm{~b}$ shows the output voltage of the buck converter $\left(\mathrm{U}_{\mathrm{H}}\right)$ and the DC bus voltage of the inverter $\left(\mathrm{E}_{1}\right)$.

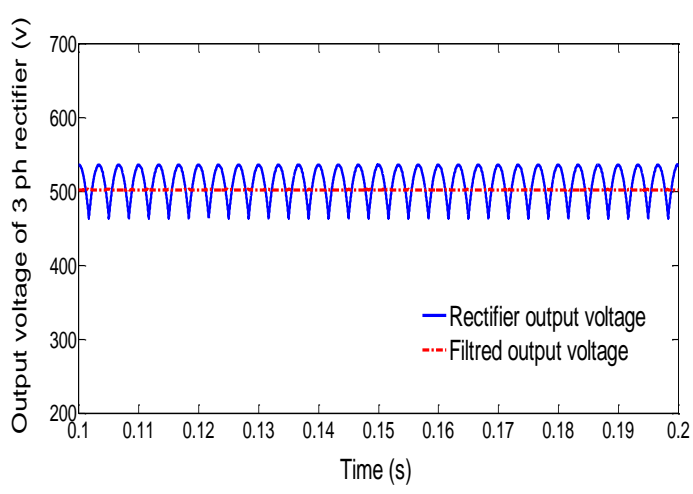

(a)

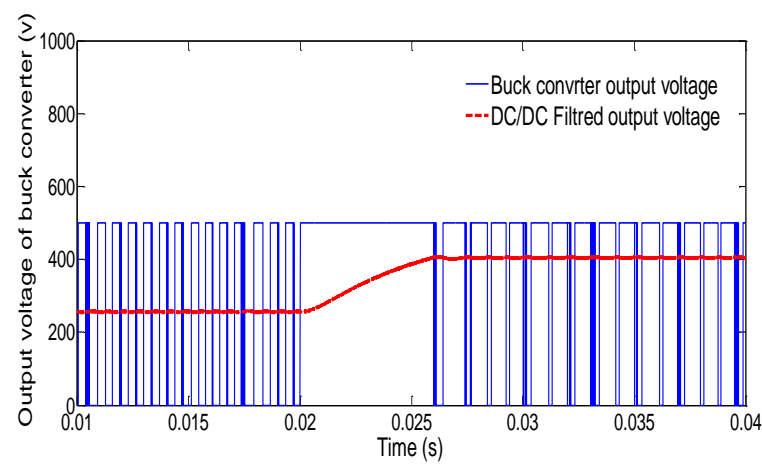

(b)

Figure 2. Simulation results in healthy state of AC/DC and DC/DC converters (a). Output voltages of three phase rectifier and filter 1, (b). Output voltages of buck converter and filter 2

Figure $3 \mathrm{a}$ illustrates the system response to a change of power reference $\left(\mathrm{P}_{\text {ref }}\right)$ from $2 \mathrm{~kW}$ to $5 \mathrm{~kW}$. One can notice a good tracking of the reference, with a very acceptable overshooting, which justifies and confirms the good tuning of the controller parameters. Figure $3 \mathrm{~b}$ shows that the voltage and load current are in phase, which confirms a very close operation of the resonance, with a maximum active power injected into the thermal load and a perfect compensation of the reactive power, which reveals the correct setting of the PLL. 


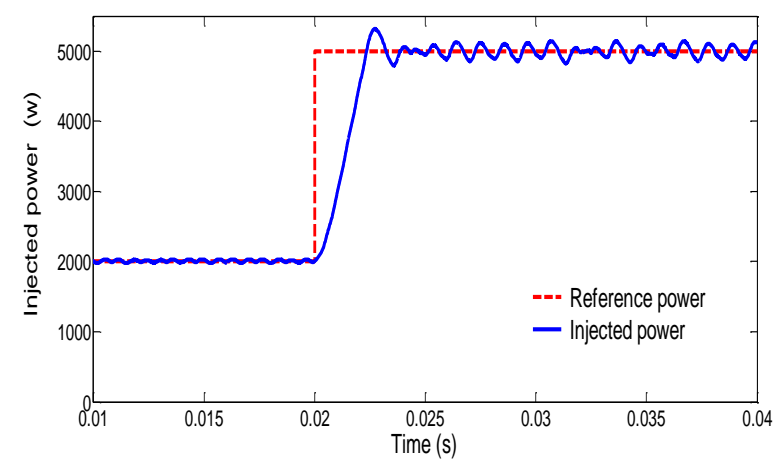

(a)

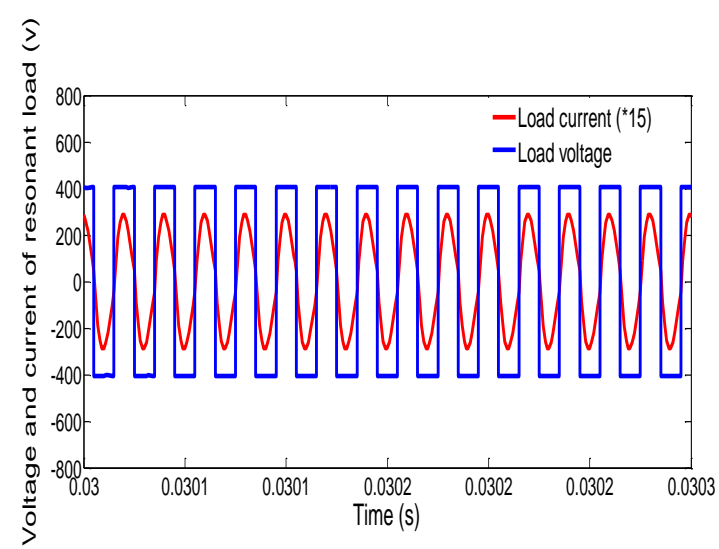

(b)

Figure 3. Simulation results in healthy state of DC/AC converter (a). Active power injected, (b). Voltage and current in the resonant load (zoom)

\section{DIAGNOSIS OF OPEN CIRCUIT FAULTS IN THREE PHASE UNCONTROLLED BRIDGE RECTIFIER}

In this part, three diagnostic techniques of diode opening defects are presented: 1) Average lines current method, 2) Spectrum analysis, 3) Current Park's vector trajectory approach. Case of diode $D_{1}$ :

\subsection{Diagnosis by average lines current method}

Once the defect of opening of the diode $\mathrm{D}_{1}$ appears, we can observe that:

a. The rectified voltage form (Figure 4.a) changes, with a new frequency $50 \mathrm{~Hz}$ instead of $300 \mathrm{~Hz}$ and a reduction of $16 \%$ of its average value in healthy mode.

b. The line current $i_{a}$ (Figure 4.b) loses its positive alternation with appearance of a negative DC component (average value). However, the other two currents $\left(i_{b}\right.$ and $\left.i_{c}\right)$ compensate the current $\left(i_{a}\right)$ and we can notice the appearance of their positive DC components.

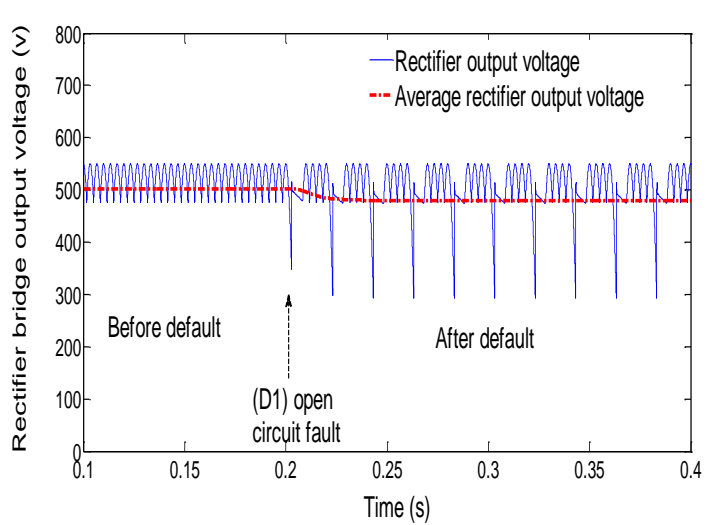

(a)

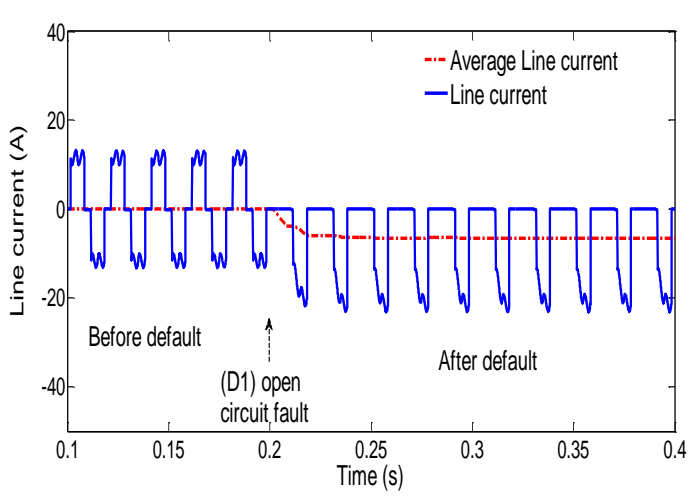

(b)

Figure 4. Simulation results after diode $\mathrm{D}_{1}$ open circuit fault of three-phase uncontrolled bridge rectifier (a). Bridge rectifier output voltage and its average value in faulty state, (b). Line current ( $\left.i_{a}\right)$ in faulty state 
Table 1 illustrates a synthesis, allowing the diagnosis and the direct location of the faulty diode, by following signs of DC components of lines currents.

Table 1. Synthesis table of diodes open circuit faults

\begin{tabular}{rccc}
\hline $\begin{array}{c}\text { Default } \\
\text { diode }\end{array}$ & $\mathrm{i}_{\mathrm{a}} \mathbf{C C}$ - sign & $\mathrm{i}_{\mathrm{b} \text { CC }- \text { sign }}$ & $\mathrm{i}_{\mathbf{c}} \mathbf{C C}-$ sign \\
\hline $\mathrm{D}_{1}$ & - & + & + \\
$\mathrm{D}_{2}$ & + & - & - \\
$\mathrm{D}_{3}$ & + & - & + \\
$\mathrm{D}_{4}$ & - & + & - \\
$\mathrm{D}_{5}$ & + & + & - \\
$\mathrm{D}_{6}$ & - & - & + \\
\hline
\end{tabular}

\subsection{Diagnosis by spectrum analysis technique}

Following an open circuit fault of diode $\mathrm{D}_{1}$, a spectral analysis is realized by a Fast Fourier Transform (FFT) of Matlab/Simulink (Figure 5.a). Figure 5.b translates well this harmonics spectrum, illustrating in detail (frequency, amplitude and phase) the list of all line current harmonics. Two steps are necessary to locate the diode in open circuit fault:

a. The harmonics spectrum of Figure 5.a allows to detect an opening fault of diodes $\mathrm{D}_{1}$ or $\mathrm{D}_{4}$ in the first arm of the bridge rectifier, with intrinsic characteristics for this type of defect: a DC component of $60 \%$ with total harmonic distortion of current (THD) of $69.20 \%$.

b. Regarding the location of the failed component, a reading of the phase of the DC component is required. For the case considered ( $\mathrm{D}_{1}$ in defect), the $270^{\circ}$ phase indicates the negative sign of the latter (Figure 5.b). For the case of diode $\mathrm{D}_{4}$ in fault, the phase would be $90^{\circ}$.

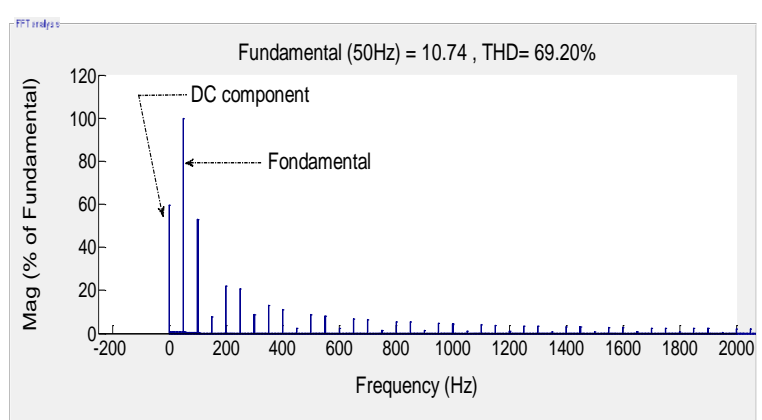

(a)

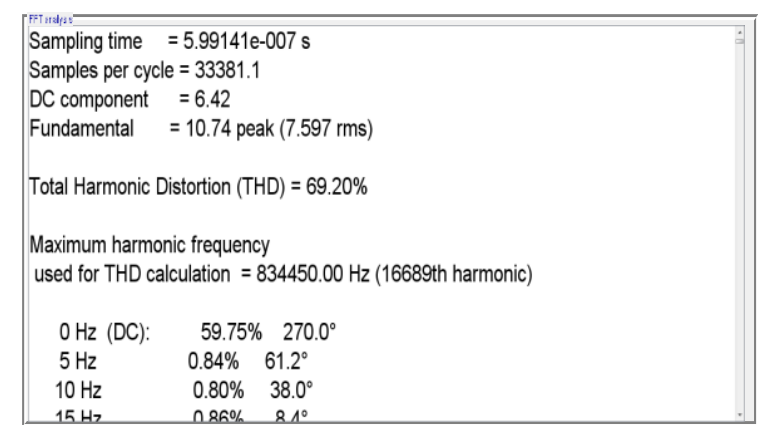

(b)

Figure 5. Spectrum analysis of the line current $\left(i_{a}\right)$, after an open circuit fault of diode $D_{1}$ (a). Harmonics spectrum (amplitude versus frequency), (b). Harmonics list (frequency, amplitude and phase)

\subsection{Diagnosis of diodes open circuit fault by current Park's vector trajectory approach}

This method is based on the Park transformation principle, which expresses the three-phase line currents in a two-phase stationary reference frame $(\alpha, \beta)$. The components of the current space vector are given by [27]:

$$
\left[\begin{array}{l}
i_{\alpha} \\
i_{\beta}
\end{array}\right]=\sqrt{\frac{3}{2}}\left[\begin{array}{ccc}
1 & -\frac{1}{2} & -\frac{1}{2} \\
0 & \frac{\sqrt{3}}{2} & -\frac{\sqrt{3}}{2}
\end{array}\right]\left[\begin{array}{l}
i_{a} \\
i_{b} \\
i_{c}
\end{array}\right]
$$

In the case of a three-wire power supply, we have:

$$
i_{a}+i_{b}+i_{c}=\mathrm{O}
$$

So we can express both components of the instantaneous current space vector by: 
$\left\{\begin{array}{l}i_{\alpha}=\sqrt{\frac{3}{2}} i_{a} \\ i_{\beta}=i_{a} \frac{1}{\sqrt{2}}+i_{b} \sqrt{2}\end{array}\right.$

In healthy case, the trajectory of the Park's vector is a symmetrical hexagon, centered on the origin (Figure 6). This pattern is considered as a reference signature of the three-phase rectifier bridge without defects. Deviations of the current space vector's trajectory indicate the presence of open circuit faults, which may affect the bridge rectifier.

Figure 6 illustrates the typical deviation of this trajectory, before and after appearance of the diode $\left(D_{1}\right)$ opening defect. Figure 7 presents a summary of the typical signatures, for each opening fault of the six diodes of the bridge rectifier.

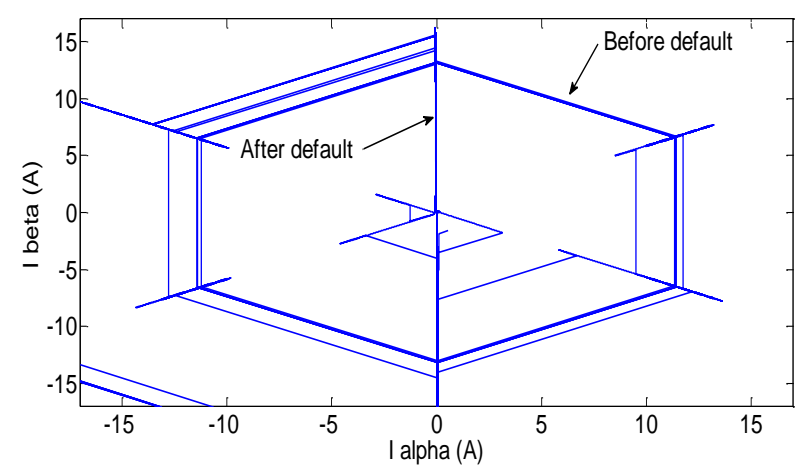

Figure 6. Trajectory of the current space vector before and after opening fault of $D_{1}$

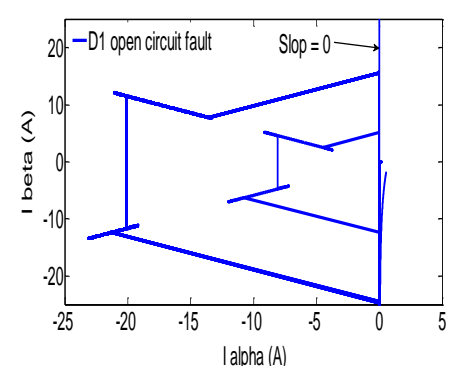

(a)

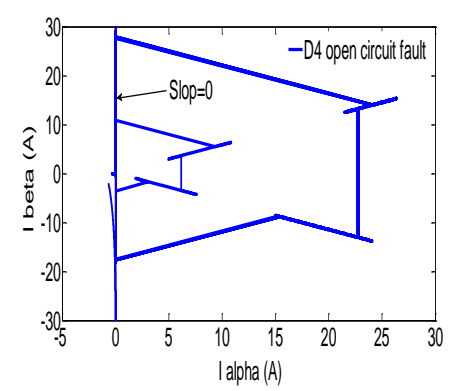

(d)

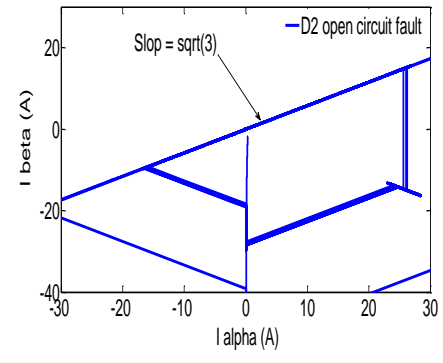

(b)

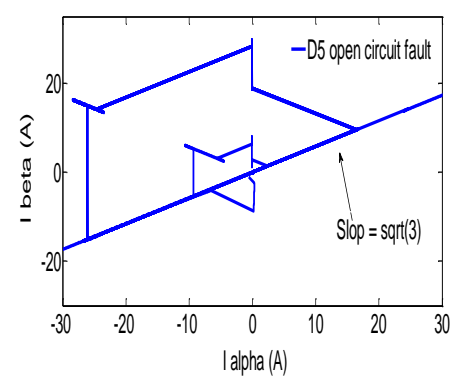

(e)

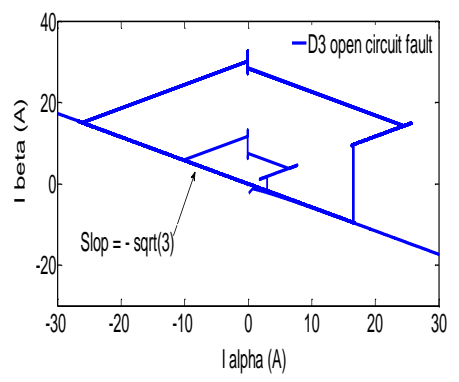

(c)

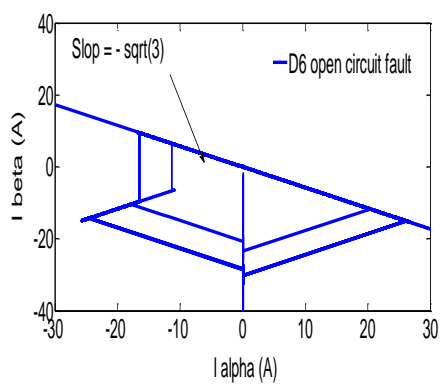

(b)

Figure 7. Typical trajectories of current space vector for each diode default 


\section{DIAGNOSIS OF BUCK CONVERTER'S POWER TRANSISTOR}

For fault diagnosis of power transistor (open or short-circuit fault) in DC/DC buck converter, an internal method, called technical analytical redundancy is used. Based on the calculation and analysis of residues between different models of buck converter (healthy and faulty cases). Two phases are necessary: fault detection and identification of the defect nature.

\subsection{Fault detection phase}

In this first phase, the residue is calculated between the output filtered voltage, of the buck converter and that provided by a reference model in healthy case. The healthy model, presented by equation 4 , is the average output voltage of the buck converter (without faults) in continuous conduction mode (equation 4):

$U_{R}=U_{\text {com }} . E_{0}$

Where: $U_{R}$ : Output voltage of reference model without faults, $E_{0}$ : Input voltage of the buck converter (filtered rectified voltage) and $U_{c o m}$ : Control voltage of buck converter (duty cycle).

Figure 8 shows the fault detection and location bloc of DC/DC converter.

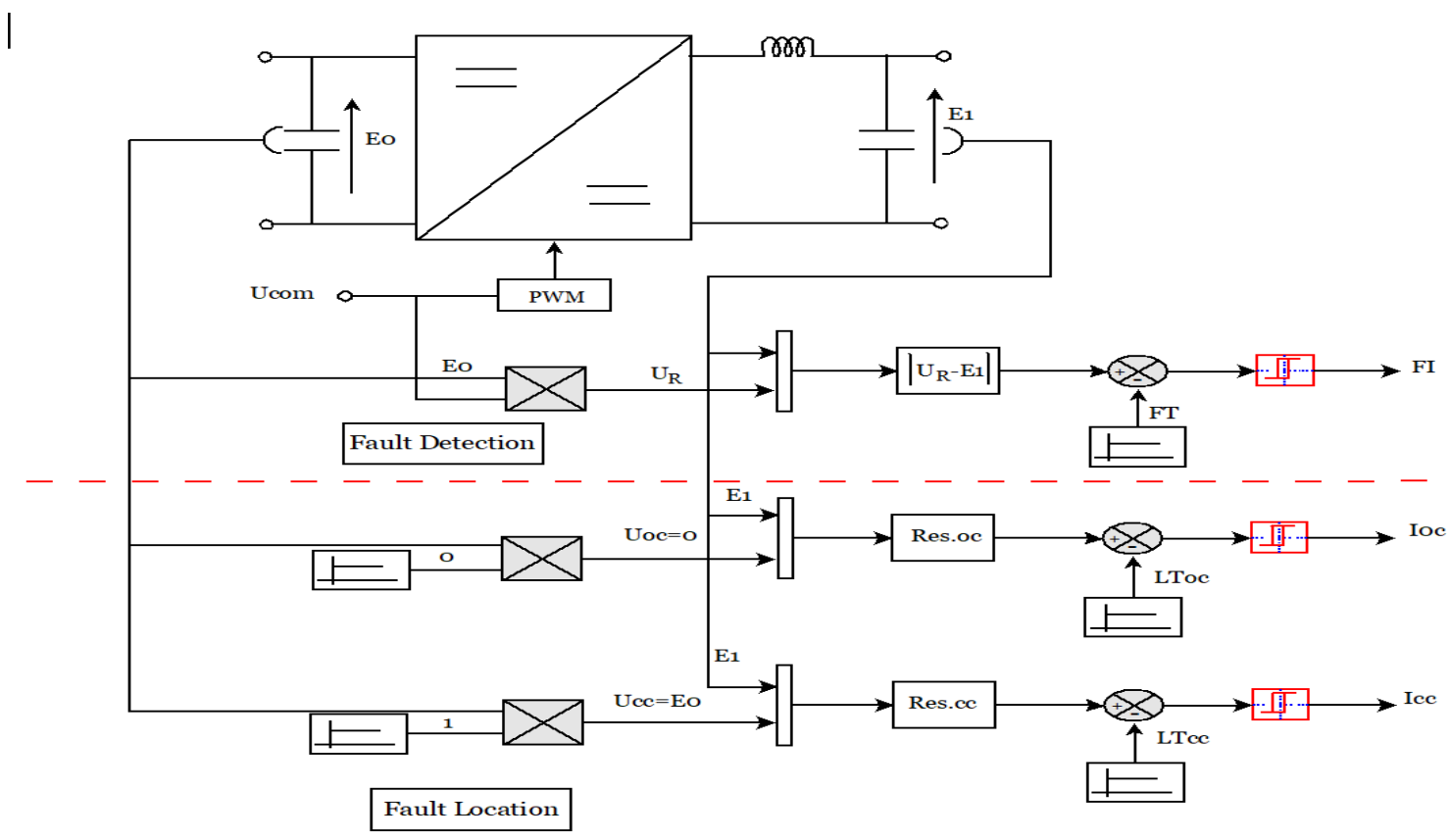

Figure 8. Fault detection and location bloc of DC/DC converter

Where: FI: Fault indicator, FT: Fault threshold, Res.oc: Residue of open circuit fault, Res.sc: Residue of short circuit fault, LToc: Location threshold of open circuit fault, LTsc: Location threshold of short circuit fault, Ioc: Indicator of open circuit fault, Isc: Indicator of short circuit fault

When considering a short-circuit fault of the power transistor at time $t=0.25 \mathrm{~s}$, the following results are obtained: Figure 9.a shows the evolution of the filtered output voltage of series chopper $\left(\mathrm{E}_{1}\right)$, compared with the buck converter reference voltage $\left(U_{R}\right)$, without faults, for a duty cycle of 0.8 . After occurrence of a short circuit fault, Figure 9.b and Figure 9.c depict respectively the evolution of the residue between these two voltages and the Boolean indicator (FI) allowing the detection of the defect, without specifying its nature. 


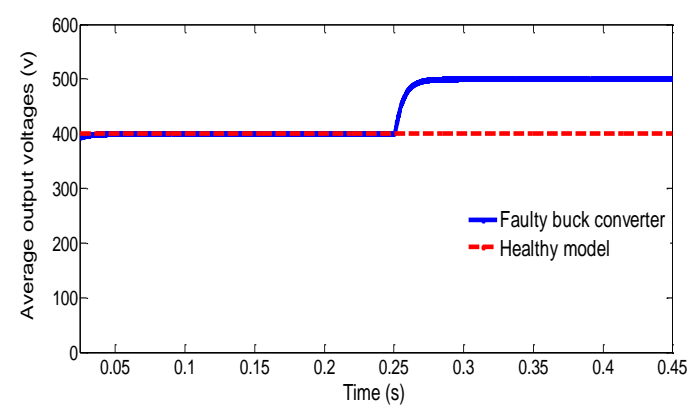

(a)

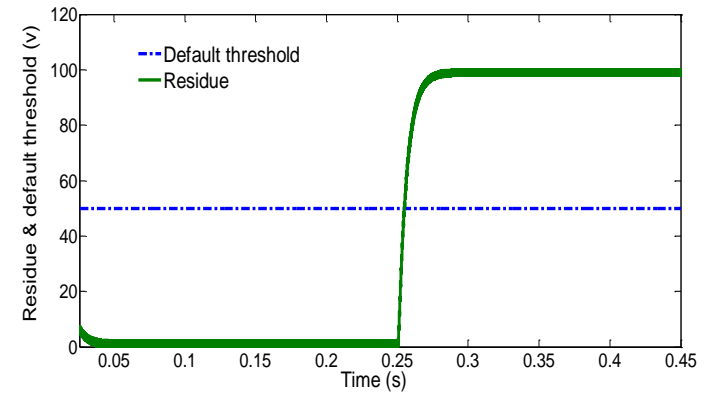

(b)

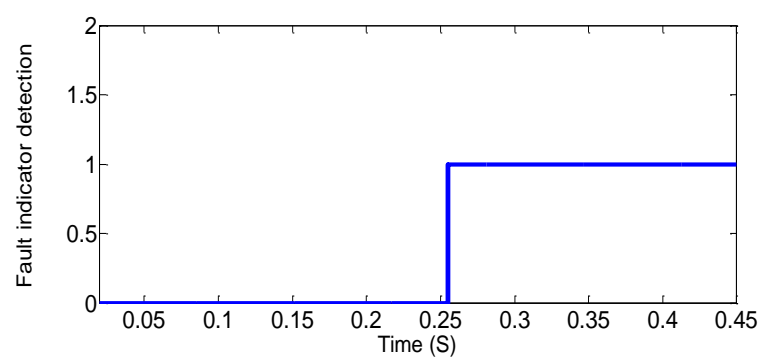

(c)

Figure 9. Simulation results after a short-circuit fault of the buck converter power transistor (a). Evolution of the filtered output voltage $\left(E_{1}\right)$ after default, (b). Evolution of voltage residue (Res), (c). Fault indicator (FI)

\subsection{Identification phase of defect nature}

To identify the nature of the fault (short circuit or open fault), the filtered output voltage, of the faulty buck converter, is compared to specific voltages for each fault (Figure 8). For the short circuit fault of the power transistor (low impedance fault), there is a permanent connection between the input and the output of DC/DC converter, the output voltage becomes: Ucc $=500 \mathrm{~V}$. However, for a high impedance fault (power transistor opening), the output voltage becomes zero: Uco $=0 \mathrm{~V}$. Figure 10 illustrates the identification of an open circuit fault of power transistor at $0.25 \mathrm{~s}$. The zero crossing of the location residue shows the perfect match between the voltage response of the DC/DC converter and that of the open fault model $(\mathrm{Uco}=0 \mathrm{~V})$.

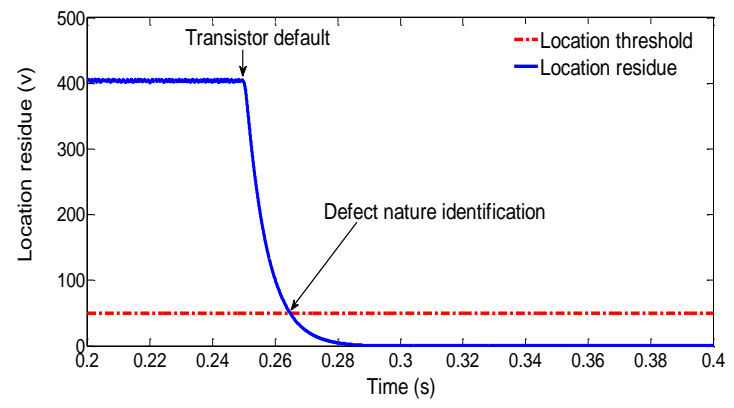

(a)

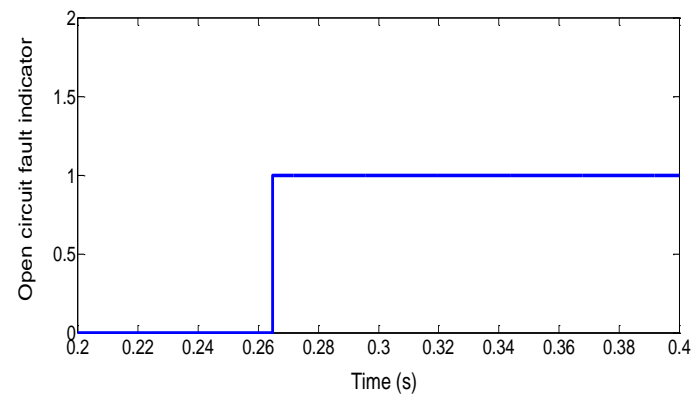

(b)

Figure 10. Simulation results after an open circuit fault of the buck converter power transistor (a). Evolution of location residue (Res.oc), (b). Indicator of the open circuit fault (Ioc) 


\section{POWER TRANSISTORS OPEN CIRCUIT FAULT DIAGNOSIS OF SERIES RESONANT INVERTER}

In this last part, we deal with a technique for diagnosing of power transistors opening faults, based on analysis of the average voltage across the resonant load and those across the power transistor $T_{1}$ or $T_{2}$ of the same arm of resonant inverter. Figure 11 shows the topology of this inverter, after an opening defect of power transistor $\mathrm{T}_{1}$.

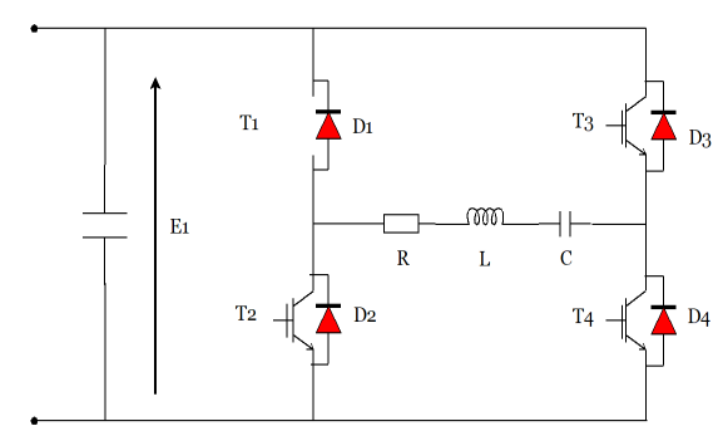

Figure 11. Series inverter topology after an open circuit fault of power transistor $\mathrm{T}_{1}$

\subsection{Inverter analysis with power transistor opening fault}

Following an open circuit fault of the power transistor $\mathrm{T}_{1}$ or $\mathrm{T}_{4}$, the voltage across the resonant load (Us) loses its positive alternation (Figure 12). On the other hand, the same defect of the power transistor $\mathrm{T}_{2}$ or $\mathrm{T}_{3}$ is manifested by the loss of the negative alternation of the same voltage. In this case, we consider, for example, an opening defect of power transistor $T_{1}$ or $T_{4}$ at time $t=0.025$ s. Figure 11 illustrates the evolution of the average output voltage of the series resonant inverter after the fault occurrence.

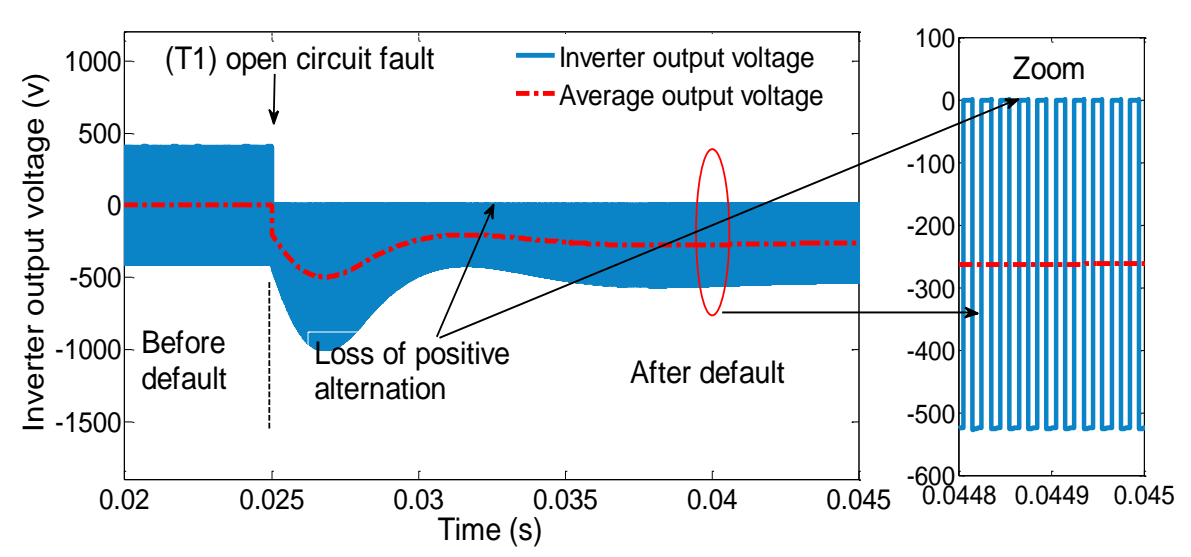

Figure 12. Inverter output voltage after an open circuit fault of power transistor $T_{1}$ or $T_{4}$

\subsection{Detection phase of power transistors open circuit faults}

The loss of the positive alternation of this output voltage explains the negative sign of its average value. Figure 13.a illustrates well the evolution of the residue between the average reference voltage (zero in healthy state) and that across the resonant load. Figure 13.b shows the Boolean indicator opening fault of transistors $T_{1}$ or $T_{4}$, without specifying the component in default. To determine which of the two power transistors is failing, a second phase of localization is necessary.

\subsection{Localization of the faulty component}

For the case of opening fault of the transistor $\mathrm{T}_{1}$ (Figure 11), it can easily be seen that the positive alternation of the load current is ensured by $\mathrm{T}_{4}$ and $\mathrm{D}_{2}$, hence the freewheel phase which explains the loss of 
the positive alternation of the series inverter output voltage, while the negative alternation of the same current is ensured by $\mathrm{T}_{2}$ and $\mathrm{T}_{3}$.

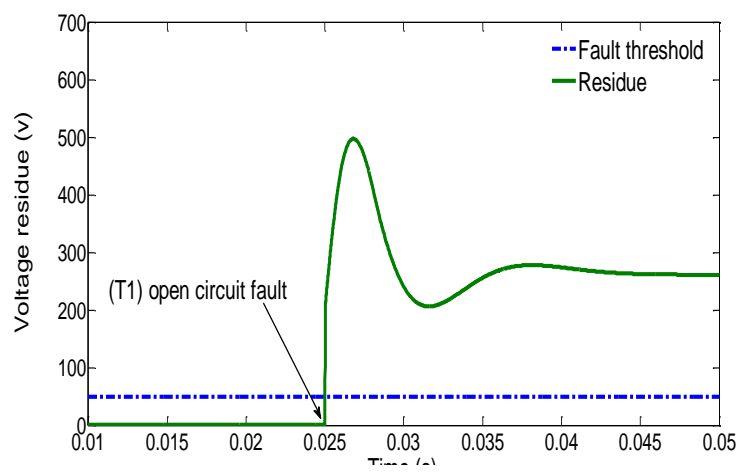

(a)

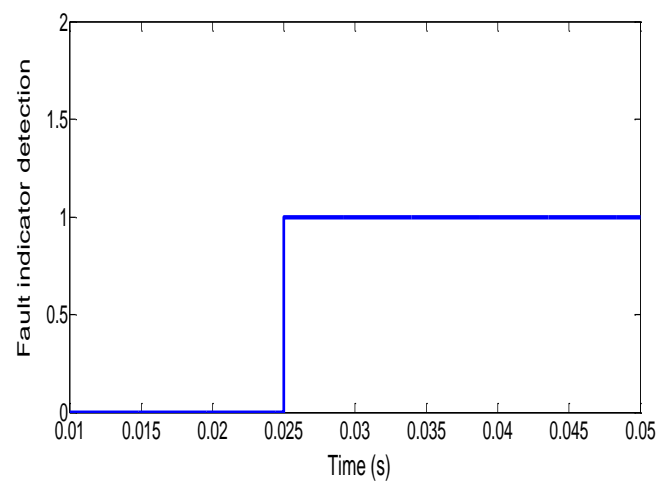

(b)

Figure 13. Fault detection of an open circuit in the first $\operatorname{arm}\left(\mathrm{T}_{1}\right.$ or $\left.\mathrm{T}_{4}\right)$ of the resonant inverter (a). Voltage residue, (b). Opening fault indicator of power transistor $\mathrm{T}_{1}$ or $\mathrm{T}_{4}$

Therefore the bidirectional switch $\left(\mathrm{T}_{2}, \mathrm{D}_{2}\right)$ is always in conduction and the bidirectional switch $\left(\mathrm{T}_{1}, \mathrm{D}_{1}\right)$ is always blocked and supports the total DC bus voltage $\left(\mathrm{E}_{1}\right)$ of the series inverter, which is well illustrated in Figure 14.

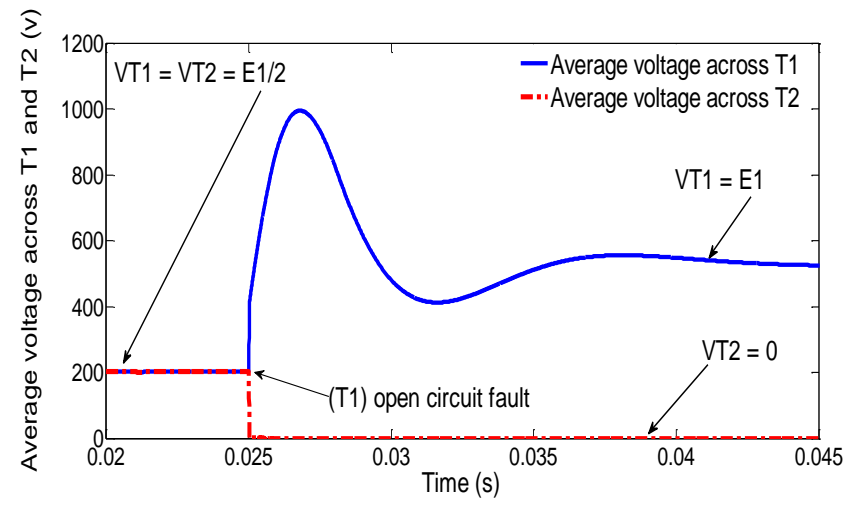

Figure 14. Average voltages across the power transistors $T_{1}$ and $T_{2}$ after an open circuit fault of $T_{1}$

After a deep analysis of the faulty series inverter, we have developed localization logic of power transistors open circuit faults (Table 2), based on:

a. The sign of average output voltage $\left(\mathrm{U}_{\mathrm{AV}}\right)$ of series inverter.

b. And the evolution of the average voltage $\left(\mathrm{V}_{\mathrm{T} 1 \mathrm{AV}}\right)$ across the power transistor $\mathrm{T}_{1}$ only.

Finally we can detect and locate the failing component with two voltage sensors only.

Table 2. Locating table of power transistors in open circuit fault

\begin{tabular}{ccc}
\hline $\begin{array}{c}\text { Default } \\
\text { transistor }\end{array}$ & $\mathrm{U}_{\mathrm{AV}}$ sign & $\mathrm{V}_{\mathrm{T} 1 \mathrm{AV}}$ \\
\hline $\mathrm{T}_{1}$ & - & $\mathrm{E}_{1}$ \\
$\mathrm{~T}_{2}$ & + & 0 \\
$\mathrm{~T}_{3}$ & + & $\mathrm{E}_{1} / 2$ \\
$\mathrm{~T}_{4}$ & - & $\mathrm{E}_{1} / 2$ \\
\hline
\end{tabular}




\section{CONCLUSION}

In this paper, several fault diagnosis techniques were presented and applied in simulation, on three static converters, which constitute the power generator of the induction heating system. For the uncontrolled three-phase bridge rectifier, the method of average lines currents proves to be the most efficient and allows a direct location of the faulty diode and requires only two current sensors. For the buck converter, the used analytical redundancy approach makes it possible to detect the fault and to identify its nature (open circuit fault or short circuit of the power transistor), but remains dependent on modeling assumptions and choice of faults thresholds. Finally, for the series resonance inverter, the average voltage technique used allows the detection of the open circuit fault and the location of the faulty power transistor, with a simple logic that requires only two voltage sensors.

\section{ACKNOWLEDGEMENTS}

I would like to thank sincerely Professor Bachir Abdelhadi, from Batna 2 University, for all his relevant comments and judicious advices and Doctor Sabir Ouchen for his the help.

\section{REFERENCES}

[1] A.C. Metaxas, St John's College University of Cambridge, UK, "Foundations of Electroheat. A Unified Approach", ISBN 047195644 9, John Wiley \& Sons, Ltd, Chichester, UK, 1996.

[2] E.J. Dede, J. Jordan, V. Esteve, "State of the Art and Future Trends in Transistorized Inverters for Induction Heating Applications", Fifth IEEE International Caracas Conference on Devices, Circuits And Systems, Punta Cana, Dominican Republic, Vol. 1, pp. 204-211, 2004.

[3] O. Lucía, P. Maussion, E. J. Dede, J. M. Burdío, "Induction Heating Technology and its Applications: Past Developments, Currents Technology, and Future Challenges", IEEE Transactions On Industrial Electronics, Vol.61, No .3, pp. 2509-2520, 2013.

[4] V. Crisafulli, "Trends in Residential and Industrial Induction Cooking: Topologies and Power Devices for High Efficiency", International Exhibition and Conference for Power Electronics, Intelligent Motion, Renewable Energy and Energy Management (PCIM), Nuremberg, Germany, pp. 1-8, 2016.

[5] P. K. Sadhu, D. Roy, N. Pal, S. Sanyal, "Selection of Appropriate Semiconductor Switches for Induction Heated Pipe-Line Using High Frequency Full Bridge Inverter ", International Journal of Power Electronics and Drive System (IJPEDS), Vol. 5, No. 1, pp. 112-118, Jul 2014.

[6] E.J. Dede, J. Jordán, V. Esteve, "The Practical Use of Sic Devices in High Power High Frequency Inverter for Industrial Induction Heating Applications", $2^{\text {nd }}$ IEEE Annual Southern Power Electronics Conference (SPEC), Auckland, New Zealand, pp. 1-5, 2016.

[7] P. K. Sadhu, P. Pal, N. Pal, S. Sanyal, "Selection of Power Semiconductor Switches in M.H.B.R.I. Fitted Induction Heater for Less Harmonic Injection in Power Line", International Journal of Power Electronics and Drive System (IJPEDS), Vol. 6, No. 1, pp. 121-128, Mar 2015.

[8] A. M. S. Mendes, A. J. Cardoso, "Diagnosis in a Rectifier-Inverter System Used in Variable Speed AC Drives, by the Average Current Park'S Vector Approach", European Power Electronics Conference, Lausanne, Suisse, pp. 19, 1999.

[9] K. Rothenhagen, F.W. Fushs, "Performance of Diagnosis Methods for IGBT Open Circuit Faults in Three Phase Voltage Source Inverters for AC Variable Speed Drives", IEEE, European Conference On Power Electronics And Applications, Dresden, Germany, pp.7-10, 2005.

[10] B. Lu, S.K. Sharma, "A Literature Review of IGBT Fault Diagnostic and Protection Methods for Power Inverters", IEEE Transactions on Industry Applications, Vol .45, No .5, pp. 1770-1777, 2009.

[11] M.E.H. Benbouzid, C. Delpha, Z. Khatir, S. Lefebvre and D. Diallo, "Faults Detection and Diagnosis in a Static Converter, Electrical Machines Diagnosis", Chap. 9, ISBN: 978-1-84821-263-3, Edited by Jean-Claude Trigeassou, John Wiley \& Sons, Inc., ISTE Ltd, Paris, pp. 271-316, 2011.

[12] K.V. Kumar, S.S. Kumar, A.I. Selvakumar, "A Review of Voltage and Current Signature Diagnosis in Industrial Drives ", International Journal of Power Electronics and Drive System (IJPEDS), Vol. 1, No. 1, pp. 75-82, Sep 2011.

[13] T. Kamel, Y. Biletskiy, C.P.Diduh,L.Chang, "Fault Diagnosis for all the Stages of the Power Electronic Converter", 25th IEEE Canadian Conference On Electrical And Computer Engineering (CCECE), Montreal, QC, Canada, pp.1-4, 2012.

[14] M. Rahiminejad, C. Diduch, M. Stevenson, L. Chang, "Open-Circuit Fault Diagnosis in 3-Phase Uncontrolled Rectifiers", 3rd IEEE International Symposium on Power Electronics for Distributed Generation Systems (PEDG), Aalborg, Denmark, pp. 254 - 259, 2012.

[15] P. S. Das, K. H. Kim, "Open-Switch Fault -Tolerant Control of a Grid-Side Converter in a Wind Power Generation System", International Journal of Power Electronics and Drive System (IJPEDS), Vol. 6, No. 2, pp. 293-304, June 2015.

[16] M. Shahbazi, E. Jamshidpour, P. Poure, S. Saadate, M.R. Zolghadri, "Open and Short-Circuit Switch Fault Diagnosis for non Isolated DC-DC Converters Using Field Programmable Gate Array", IEEE Transactions On Industrial Electronics, Vol .60, No.9, pp. 4136-4146, 2013. 
[17] D. V. Ramana, S. Baskar, "Incipient Fault Detection of the Inverter Fed Induction Motor Drive", International Journal of Power Electronics and Drive System (IJPEDS), Vol. 8, No. 2, pp. 722-729, June 2017.

[18] C.V. Suru, E. Subtirelu, M. Lincă, "Study of Energetic Performances of a Power Static Converter with Current Source and Parallel Resonance Inverter for Induction Heating Applications", 8th International Symposium On Advanced Topics In Electrical Engineering (ATEE), Bucharest, Romania, pp. 1-6, 2013.

[19] M. Saravanan, A. Ramesh Babu, "High Power Density Multi-Mosfet-Based Series Resonant Inverter for Induction Heating Applications", International Journal of Power Electronics and Drive System (IJPEDS), Vol. 7, No. 1, pp. 107-113, Mar 2016.

[20] V. Esteve, J. Jordán, E.S. Kilders, E.J. Dede, E. Maset, J.B. Ejea, A. Ferreres, "Improving the Reliability of Series Resonant Inverters for induction Heating Applications", IEEE Transactions on Industrial Electronics, Vol .61, No .5, pp. 2564-2572, 2014.

[21] J. Walter, G. Ceglia, V.Guzman, M. Gimenez, "Control Model of a Closed Loop Power - Controlled Series Type Resonant Induction Heating System", IEEE European Conference on Power Electronics and Applications (EPE), Aalborg, Denmark, pp. 1-8, 2007.

[22] M. Periasamy, C. Umayal, "Improved Time Responses of PI \& FL Controlled SEPIC Converter based Series Resonant Inverter-fed Induction Heating System", International Journal of Power Electronics and Drive System (IJPEDS), Vol. 9, No. 1, pp. 305-315, Mar 2018.

[23] N. S. Bayindir, O. Kukrer, M. Yakup, "DSP-Based PLL-Controlled 50-100 Khz-20 Kw High-Frequency Induction Heating System for Surface Hardening and Welding Applications", IET, IEE Proceedings - Electric Power Applications, Vol. 150, No .3, pp. 365-371, 2003.

[24] B. Meziane, H. Zeroug, "Improved Efficiency Determination for a PLL-Controlled Series Resonant Inverter for Induction Metal Surface Hardening", IEEE Industry Applications Society Annual Meeting, Addison, TX, USA, pp.1- 8, 2015.

[25] P. Herasymenko, V. Hutsaliuk, V. Pavlovskyi, O. Yurchenko, "A Software Phase-Locked Loop of Control System of a Series-Resonant Voltage-Source Inverter for Induction Heating Equipment", First IEEE Ukraine Conference on Electrical And Computer Engineering (UKRCON), Kiev, Ukraine, pp. 384-389, 2017.

[26] Y.L. Cui , K. He, Z.W. Fan, Hao.L. Fan, "Study on DSP-Based PLL-Controlled Super Audio Induction Heating Power Supply Simulation", International Conference On Machine Learning And Cybernetics (ICMLC), Guangzhou, China, Vol .2, pp. 1082-1087, 2005.

[27] D. Diallo, M. E. H. Benbouzid, D. Hamad, X. Pierre, "Fault Détection and Diagnosis in an Induction Machine Drive: A Pattern Recognition Approach Based on Concordia Stator Mean Current Vector", IEEE Transactions On Energy Conversion, Vol .20, No .3, pp. 512 -519, 2005.

\section{BIOGRAPHIES OF AUTHORS}

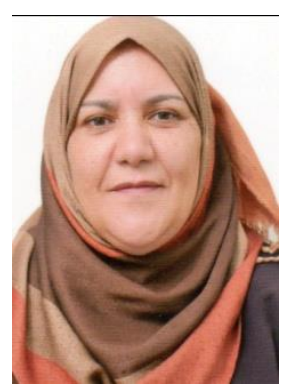

Ouahiba Fadli was born in Khenchela, Algeria. She received the Magister degree in electrical engineering - power electronics from the faculty of technology, Batna University, Algeria, in 2006. She is currently a lecturer at the Institute of Health and Safety, Batna 2 University. She pursues her doctoral program in electrical engineering at the same university. Her research interests are: power electronics, induction heating systems, fault detection and diagnosis in power converters. E-mail : wafadli@yahoo.fr

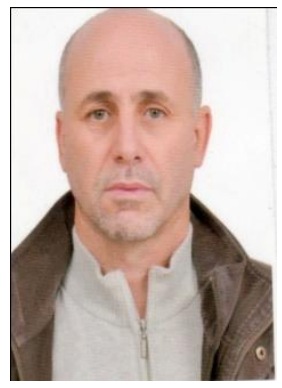

Mohamed Lokmane Bendaas (Prof) was born in Batna, Algeria. He received his M.Sc. degree in electrical engineering from Batna University, Algeria, in 1989, and the $\mathrm{PhD}$ degrees in electrical engineering from the National Polytechnic Institute of Grenoble, France, in 1993. Currently He is a Professor at the department of electrical engineering, Batna 2 University, Algeria. His research interests are: power electronics, fault detection and diagnosis in power converters, FACTS, active filtering and renewable energy. E-mail : mlbendaas@yahoo.fr 


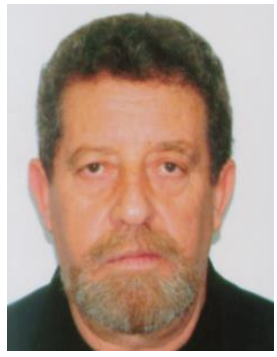

Rachid Abdessemed (Prof, $\mathrm{PhD}$ ) was born in Batna, Algeria and got the MSc and PhD degrees in electrical engineering from Kiev Polytechnic Institute and Electrodynamic Research Institute Ukrainian Academy of Sciences in 1982. Currently, he is director of the LEB research laboratory. His research interests are the design and control of induction machines and converters, reliability, magnetic bearings and renewable energy. E-mail : rachid.abdessemed@gmail.com 